\title{
Subclinical pulmonary abnormalities in juvenile dermatomyositis
}

\author{
Adriana M Sallum ${ }^{1 *}$, Douglas Coutinho ${ }^{2}$, Claudine Veiga ${ }^{2}$, Lisa Suzuki ${ }^{3}$, Luiz Antonio Nunes $^{3}$, Clovis A Silva $^{1}$, \\ Joaquim Rodrigues ${ }^{2}$
}

From 21st European Pediatric Rheumatology (PReS) Congress

Belgrade, Serbia. 17-21 September 2014

\section{Introduction}

Pulmonary involvement in juvenile dermatomyositis (JDM) is frequent and associated with poor outcome. However, a systematic assessment of pulmonary function and high-resolution computed tomography (HRCT) was rarely reported in this population.

\section{Objectives}

To assess pulmonary function and HRCT in JDM patients and to evaluate possible associations between pulmonary abnormalities and disease activity, cumulative damage and health-related quality of life (HRQL) scores.

\section{Methods}

A cross-sectional study was performed in 20 JDM patients. Pulmonary function test included spirometry, body plethysmography and diffusion capacity for carbon monoxide (DLCO). They were also carried out six-minute walk test (6MWT) and HRCT scan. Disease activity score (DAS), childhood myositis assessment scale (CMAS), myositis damage index (MDI) and HRQL (Pediatric Quality of Life Inventory - PedsQL) data were also assessed

\section{Results}

The mean age was 11.6 years (6-18). Subclinical mild/ moderate obstruction according to American Thoracic Society criteria was observed in $35 \%$ and DLCO was reduced in $20 \%$ of JDM patients. Spirometric and/or DLCO abnormalities were observed in $45 \%$ of patients. In plethysmography, reduced total lung capacity (TLC) and conductance were observed in $25 \%$ and $50 \%$ of JDM patients, respectively. In contrast, increased resistance and

Pediatric Rheumatology Unit - Pediatrics Department, Instituto da Criança HC FMUSP, São Paulo, Brazil

Full list of author information is available at the end of the article residual volume (RV)/TLC were evidenced in $10 \%$ and $35 \%$ of JDM patients, respectively. Thirteen patients underwent HRCT and 8 had alterations: interstitial lung disease in 6 and a mixed pattern in two. A positive correlation was observed between DAS and ratio between forced expiratory volume in one second and vital capacity (VEF1/ CV) $(r=+0.50, p=0.003)$, conductance $(r=+0.46, p=0.045)$ and HRCT score $(\mathrm{r}=+0.60, \mathrm{p}=0.003)$. A positive correlation was observed between CMAS and VEF1/CV $(r=+0.47$, $\mathrm{p}=0.042)$, DLCO $(\mathrm{r}=+0.67, \mathrm{p}=0,002)$ and 6MWT $(\mathrm{r}=+0.54$, $\mathrm{p}=0.048$ ), and negative correlation between DAS and HRCT score $(\mathrm{r}=-0.63, \mathrm{p}=0.021)$. Correlations were identified between MDI and conductance $(r=+0.72, p=0.0004)$, DLCO $(r=-0.46, p=0.042)$ and HRCT score $(r=+0,81$, $\mathrm{p}=0.0008)$; and between PedsQL and VEF1/CV $(\mathrm{r}=+0.45$, $\mathrm{p}=0.046)$, conductance $(\mathrm{r}=-0.60, \mathrm{p}=0.006)$ and HRCT score $(r=+0.62, p=0.024)$. Correlations were also observed between HRCT score and VEF1/CV $(\mathrm{r}=-0.64, \mathrm{p}=0.017)$, forced expiratory flow between 25 and $75 \%$ of vital capacity $(\mathrm{FEF} 25 \%>75 \%)(\mathrm{r}=-0.59, \mathrm{p}=0.035)$ and conductance $(\mathrm{r}=+0.78, \mathrm{p}=0.0018)$.

\section{Conclusion}

Subclinical pulmonary abnormalities were frequent in this rare idiopathic inflammatory myopathy. Importantly, these findings may be related to disease severity and activity, and may influence HRQL of these patients.

\section{Disclosure of interest}

None declared.

\section{Authors' details}

${ }^{1}$ Pediatric Rheumatology Unit - Pediatrics Department, Instituto da Criança HC FMUSP, São Paulo, Brazil. ${ }^{2}$ Pediatric Pulmology Unit -Pediatrics

Department, Instituto da Criança - HC FMUSP, São Paulo, Brazil. ${ }^{3}$ Pediatric Radiology Unit - Pediatrics Department, Instituto da Criança - HC FMUSP, São Paulo, Brazil. 
- Convenient online submission

- Thorough peer review

- No space constraints or color figure charges

- Immediate publication on acceptance

- Inclusion in PubMed, CAS, Scopus and Google Scholar

- Research which is freely available for redistribution 